The $8^{\text {th }}$ International Conference of the Slovenian Society for Non-Destructive Testing

"Application of Contemporary Non-Destructive Testing in Engineering"

September 1-3, 2005, Portorož, Slovenia, pp. 323-333

\title{
MEASUREMENT OF ACOUSTIC EMISSION AND DEFORMATIONS IN LASER CUTTING OF DEEP-DRAWN SHEET PARTS
}

\author{
J.M. Slabe, T. Kek, J. Grum \\ University of Ljubljana, Faculty of Mechanical Engineering, \\ Aškerčeva 6, 1000 Ljubljana, Slovenia, \\ E-mails: janezmarko.slabe@fs.uni-lj.si, tomaz.kek@fs.uni-lj.si, \\ janez.grum@fs.uni-lj.si
}

\begin{abstract}
The paper treats the results obtained in simultaneous measurements of acoustic emission with PZT AE sensors and of deformations with resistance measuring rosettes carried out during and immediately after laser cutting-out of a deep-drawn sheet product, i.e. mudguard. The presence of a field of residual stresses produced by deep-drawing is characteristic of deep-drawn products. In the course of laser trimming and cutting-out the residual stresses get released, which affects the deformation of the deep-drawn mudguard concerned. The deformation was measured at two measuring points chosen with the resistance measuring rosettes. To describe the changes in the material, acoustic emission was measured at the same points. The two phenomena were then analyzed. A goal of the study presented in this paper was primarily to analyze the sources of acoustic emission present during and immediately after laser cutting. It was found that the main source of acoustic emission during laser cutting was the cutting gas jet. The "true" acoustic emission occurring during the laser-cutting process and immediately after cutting of the mudguard is related to the release of the residual stresses present in the deepdrawn sheet product and to the processes in material generated by the absorbed laser light. The energy of the acoustic emission signals recorded during the cutting process and immediately after cutting, the number of AE hits detected by individual sensor in a unit of time and their cumulative value indicate a significant connection with the phenomena in the material and with the material deformations, which may enable optimization of the laser-cutting technology, including the selection of the cutting conditions.
\end{abstract}

Keywords: Acoustic emission, Deformation, Laser cutting

\section{Introduction}

\subsection{Laser cutting}

Laser cutting is classified among the thermal cutting processes in which a material is cut by means of local melting and material evaporation [1]. In the laser cutting process the heat generated by a laser beam at the point of its interaction with the workpiece surface is used. The cutting efficiency can be considerably increased by the use of a cutting gas jet. It is oxygen that is commonly used as the cutting gas. As oxygen exothermally reacts with iron ions and the ions 
of alloying elements, an additional heat source is thus provided for the cutting process. The oxygen flow can also serve for the elimination of the evaporated material and the melt from the cutting front. In case an inert gas is used, this one shields the cut surface against oxidation and accelerates the elimination of the melt formed from the cutting front.

Laser cutting is the most frequent application of lasers in manufacture. In comparison to other cutting processes, it has several advantages. It belongs to the most rapid cutting processes, the forces acting on a product during cutting being negligible; therefore, no particular clamping of the workpieces is required in cutting of the thinnest materials. The level of noise is low. Cutting may proceed in different directions in a plane and in space, which enable efficient cutting-out and trimming of shaped sheet parts. The laser cutting process is relatively easy to automate and it has good chances of adaptive control. Laser light may be used to cut almost all materials. Some difficulties, however, may be encountered with highly reflective materials because of low efficiency of the incident-light. In those cases less incident-light is transformed to heat energy and a constant energy input is hard to obtain.

\subsection{Acoustic emission (AE)}

Acoustic emission is generally defined as a acoustic wave motion, i.e., vibration of material particles, generated by energy release at local events in a material. For acoustic emission the abbreviation "AE" (see standard EN 1330-9) is frequently used. A prerequisite for the $\mathrm{AE}$ generation is a mechanical or thermal influence exerted on the object by the environment. AE sources can be very different. Roughly they can be grouped into sources of discrete AE, with which the AE activity stops after a certain time, and sources of continuous AE. Typical sources of discrete $\mathrm{AE}$ are for example crack propagation, material fracture or collision of two masses on macro level and microcrack formation or propagation, dislocation slippage across a slip plane, friction among grain boundaries, phase transformations etc. on micro level. Typical sources of continuous AE are for example friction among slip surfaces, plastic deformation of a material during machining, gas or fluid leakage from vessels or pipes etc.

The method of AE measurement is known mainly as a non-destructive method applied to testing of materials and structures permitting on-line control of the state of different object used in different applications. With advances in computer technology, measurement technique, and software the number of AE applications has strongly increased. Consequently also the extent of testing and prediction of the state of materials or evaluation of the integrity of objects increased [2]. The suitability of this method for evaluation and control of object integrity is guaranteed by numerous American (ASTM) [3] and European (EN) standards [2].

AE measurement can be efficiently applied to control of various production processes such as classical machining processes. With these processes AE measurement is applied for on-line control of cutting-tool wear and, indirectly for on-line control of product-surface quality [4-7]. In contrary just a few studies on the control of various welding [8] and particularly laser processes using AE measurement can be found in technical literature. Even less data are available on the application of AE measurement for on-line control of these processes in industry.

In laser processes there is no mechanical contact between the workpiece and the laser beam (tool). The workpiece surface is simply irradiated by laser light. But several phenomena occur, due to interaction between laser light and material, which induce AE. Such phenomena are the evaporation of the workpiece material and an absorbent, phase transformations in the material, material melting and solidification, thermal deformations of the material, deformations due to residual-stress releasing etc. These numerous sources of the "true" AE can give with an efficient on-line and/or off-line analysis of recorded AE signals generated by these sources very useful information for the evaluation of process quality. Accurate determination of sources of recorded AE signals is a very demanding and difficult task. Beside sources of the "true" AE other sources of $\mathrm{AE}$ must be considered with the laser processes. In these processes flow of cooling and/or shielding and/or assistant (with added particles of the filler material) and/or cutting gas represent very dominating $\mathrm{AE}$ source [9]. AE can be also generated due to the motion of the parts of the 
laser processing system. AE signal induced by the gas flow is in general considered as a noise which can be hardly distinguished from the "true" AE signals. However, in case one wishes to control the gas flow or adding of the filler material using AE measurement useful information can be obtained for this signal. Noise induced by the motion of the parts of the laser processing system is in minority and can b easily distinguished from the "true" AE signals.

\subsection{Deformations and residual stresses}

Material deformations during laser cutting of deep-drawn products will occur mainly due to the release of a field of residual stresses present in these products. The residual stresses present result from a manufacturing process such as forming, mechanical treatment, welding etc. They may produce unwanted effects during further processing. In laser trimming and cutting-out of a deep-drawn part the stresses get released, the new equilibrium of internal stresses is established, which is related to the material deformation. The deformations resulting from residual-stress releasing can be measured, during the cutting process, with resistance measuring rosettes. The measuring rosette must be placed on the deep-drawn part surface prior to laser cutting. Placing of the measuring rosette on a suitable chosen measuring point on the deep-drawn part surface will provide useful information on deformation generation in the deep-drawn part during the laser cutting process.

\section{Experimental procedure}

\subsection{Description of a deep-drawn mudguard}

Deep-drawn mudguards are made of steel sheet (1.0338 W.Nr.) of $1.5 \mathrm{~mm}$ in thickness. This steel is frequently used in the automobile industry to produce body parts. Sheet shows isotropic mechanical properties prior to deep-drawing process. A simplified picture of a deep-drawn semiproduct, from which the left and right mudguards are cut out, is shown in Fig. 1. The figure also shows the two measuring points at which AE sensors and resistance measuring rosettes were located. The two measuring points were located on the right mudguard and were chosen at the locations where relatively strong longitudinal and transverse residual stresses, i.e. relatively strong deformations due to residual-stress releasing during laser cutting, could be expected.

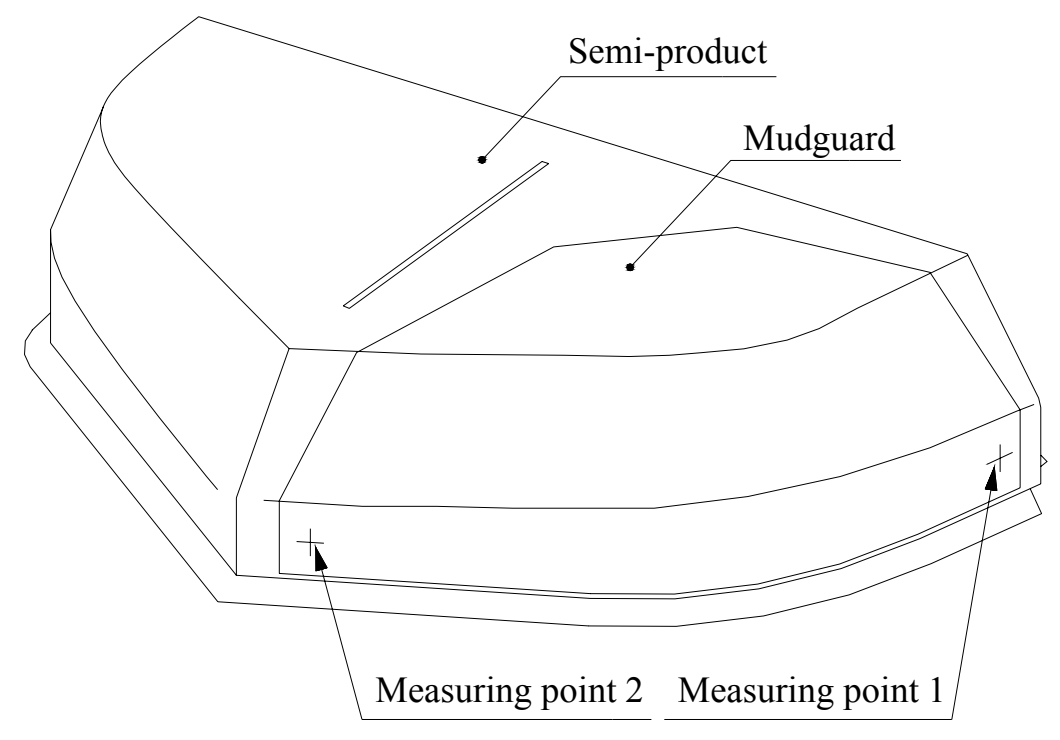

Fig. 1: Deep-drawn semi-product; definition of measuring points. 


\subsection{Laser-cutting conditions}

Laser cutting of the deep-drawn semi-product was carried out with an industrial $\mathrm{CO}_{2}$ laser Spectra Physics 820 . The laser beam showed the Gaussian distribution of power $\left(\mathrm{TEM}_{00}\right)$. The cutting gas used was oxygen. The laser-beam output power and the travel speed were chosen with reference to the complexity of he shape at the location of cutting the deep-drawn semiproduct. The laser-beam power at individual cutting-path sections was varied between $300 \mathrm{~W}$ and $400 \mathrm{~W}$ and laser-beam travel speed between 700 and $1300 \mathrm{~mm} / \mathrm{min}$. The laser-beam outlet diameter was $1.1 \mathrm{~mm}$ and the cutting-gas pressure $0.25 \mathrm{MPa}$. During laser cutting the semiproduct was rigidly clamped at a fixed machining table. Only the 5-axis laser head was moving. The mudguards were cut out in two different ways (mode 1 and mode 2) shown in Fig. 2. Two different modes were chosen due to optimisation of the laser-cutting technology of the deepdrawn semi-product.
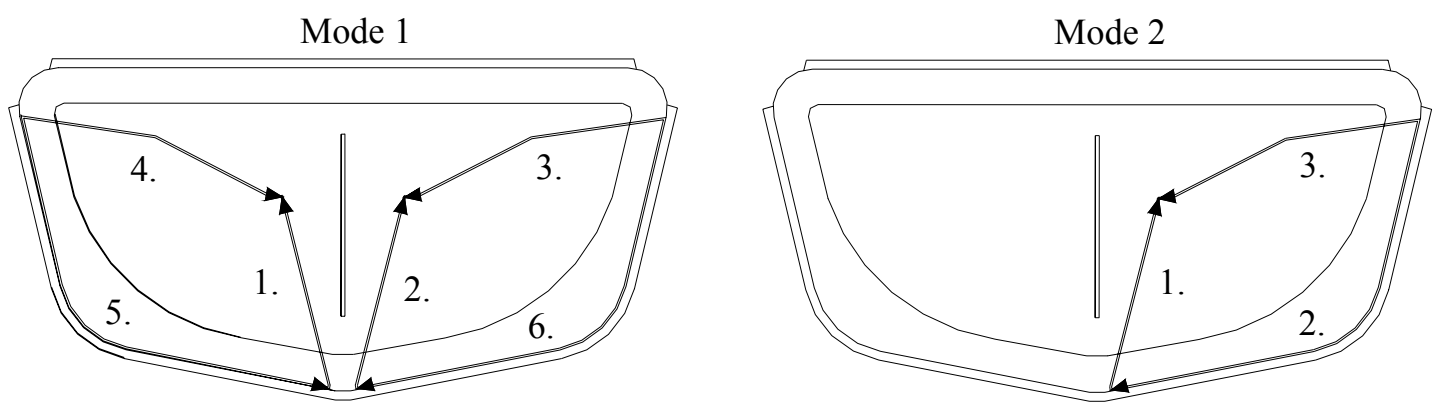

Fig. 2: Modes of cutting mudguards out of deep-drawn semi-product.

\subsection{Measurement of acoustic emission}

$\mathrm{AE}$ was measured during laser cutting and immediately after cutting-out of the mudguard. For $\mathrm{AE}$ measurement, a measuring system Vallen AMSY4, product of Vallen-Systeme GmbH, Germany was used. The measuring system included a base unit AMSY4-MC2, two signal preamplifiers AEP4, two piezoelectric AE sensors VS150-M with a frequency range of 100-450 $\mathrm{kHz}$, and adequate software.

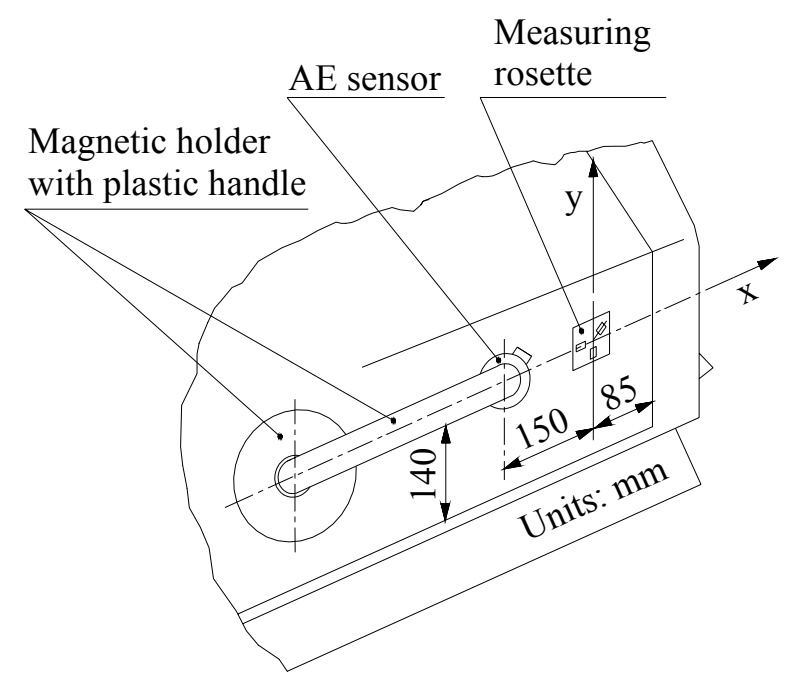

a) Measuring point 1

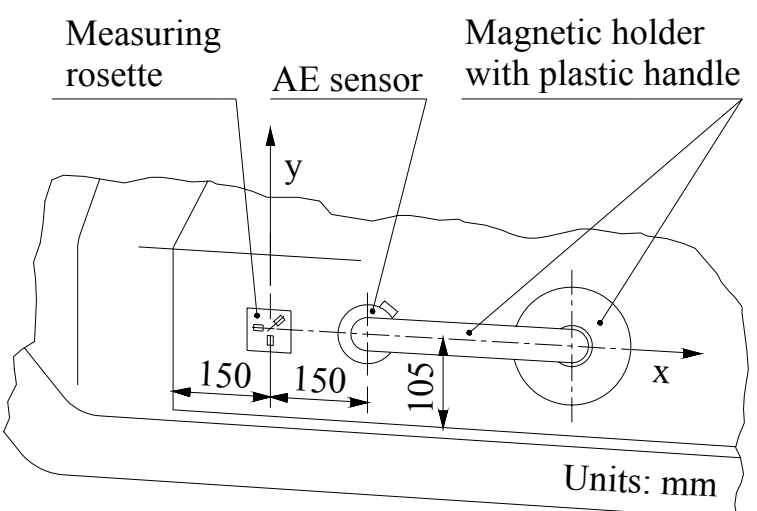

b) Measuring point 2

Fig. 3: Location of AE sensors and resistance measuring rosettes at semi-product (details of Fig. 1). 
The position of the piezoelectric AE sensors at the measuring points 1 and 2 is shown in Fig. 3 . In order to provide a good contact between the sensors and the sheet surface, i.e. for a good AE transmission from the mudguard to the AE sensor, a thin layer of silicon grease was applied. Because of the vertical position of the sensor an additional pressure force of several $\mathrm{N}$ was applied too. The pressure force was supplied by a magnetic holder with a plastic handle. Thus the stability of the sensors at the measuring points chosen was ensured. The threshold of AE signal sensing was set at $40 \mathrm{~dB}$.

AE measurement was performed:

- at laser-head travel along a trajectory of cutting-out of the mudguard with no cutting gas jet and no laser-beam activated;

- at laser-head travel along a trajectory of cutting-out of the mudguard with a cutting gas jet and no laser-beam activated;

- at laser-head travel along a trajectory of cutting-out of the mudguard with a cutting gas jet and laser-beam activated, i.e., at laser cutting of the mudguard out of the deep-drawn semiproduct.

In all three cases the laser-head travelled along the trajectory of the mode 1 of cutting-out the mudguard. Thus the individual influences on the AE generation were analysed, i.e. the influence of the motion of the parts of the laser processing system, cutting gas jet, and cutting itself could be determined.

\subsection{Measurement of deformations}

The mudguard deformation was measured with a resistance measuring rosette CEA-06-062UL120, product of Vishay Measurement Group $\mathrm{GmbH}$, Germany. The measuring rosette was connected to a personal computer via the pre-amplifier and a computer card PCI-6024E, product of National Instruments. The resistance of the individual legs of the measuring rosette amounted to $120 \mathrm{Ohm}$. The resistance measuring rosettes chosen permit measurement of deformation in three different axes, i.e., in direction $\mathrm{x}, \mathrm{y}$ and at an angle of $45^{\circ}$ with reference to $\mathrm{x}$ and $\mathrm{y}$. The arrangement and orientation of measuring rosette legs at the individual measuring points are shown in Fig. 3.

\section{Experimental results}

\subsection{AE sources during and after the laser-cutting process}

In this sub-heading the results of AE measurement obtained:

- with laser-head travel along the trajectory of cutting-out of the mudguard with no cutting gas jet and no laser-beam activated,

- with laser-head travel along the trajectory of cutting of the mudguard out of the deepdrawn semi-product with a cutting gas jet and no laser-beam activated, and

- in laser cutting of the mudguard out of the deep-drawn semi-product

will be discussed.

a) Laser-head travel with no cutting gas jet and no laser-beam activated

The results obtained in AE measurement during laser-head travel along the trajectory of cuttingout of the mudguard with no cutting gas jet and no laser-beam activated are not presented separately. In this case there is no AE in a frequency range between 100 and $450 \mathrm{kHz}$.

\section{b) Laser-head travel with cutting gas jet and no laser-beam activated}

It is quite a different case when the laser-head travel is accompanied by a cutting gas jet. The diagram in Fig. 4a indicates that the cutting-gas jet generates strong $\mathrm{AE}$ of almost constant intensity expressed by a number of $\mathrm{AE}$ hits per unit of time. In the meantime, when the laser head is travelling from the end of the trajectory of the preceding cut to the beginning of the 
trajectory of the new cut and the cutting gas jet is shut-off, there is no AE. The constant AE intensity with the cutting gas jet present shows also in a constant curve slope in the diagram in Fig. 4b. The diagram shows a cumulative number of AE hits as a function of time. The absence of AE when the cutting gas jet is shut-off is clearly seen in Fig. $4 \mathrm{~b}$ as a series of flat steps at the increasing curve. Taking into account the unlimited duration of the majority of the AE signals captured in the presence of the cutting-gas jet it can be inferred that the cutting-gas jet generates mostly the continuous AE.

\section{Mode 1 of cutting-out the mudguard}

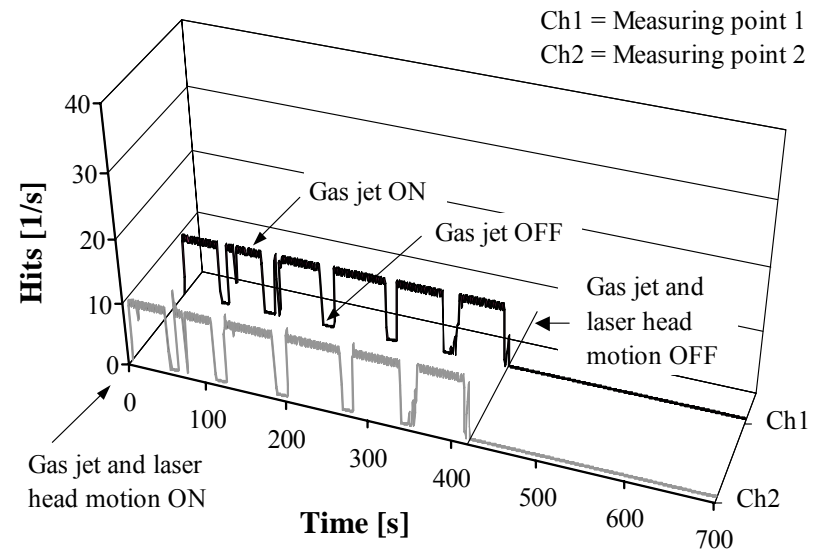

a)

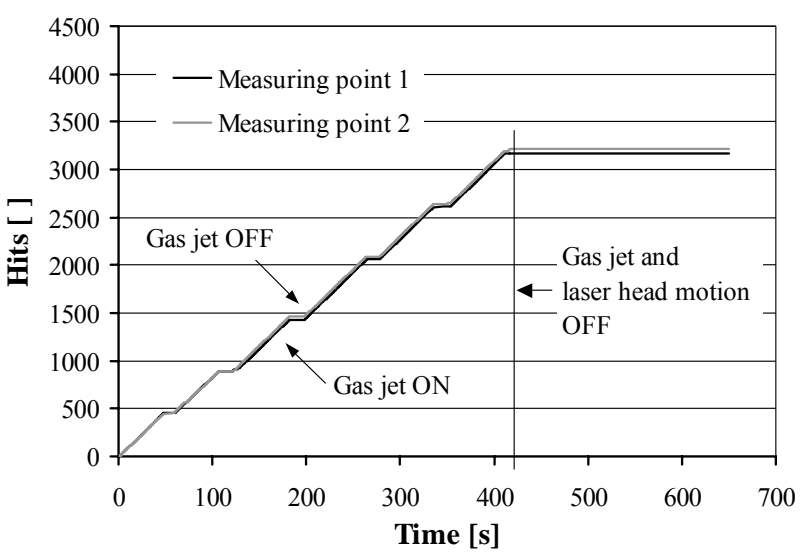

b)

Fig. 4: a) Number of AE hits per unit of time. and b) cumulative number of AE hits of individual sensors as a function of travel time of laser head with just cutting gas jet present - no cutting.

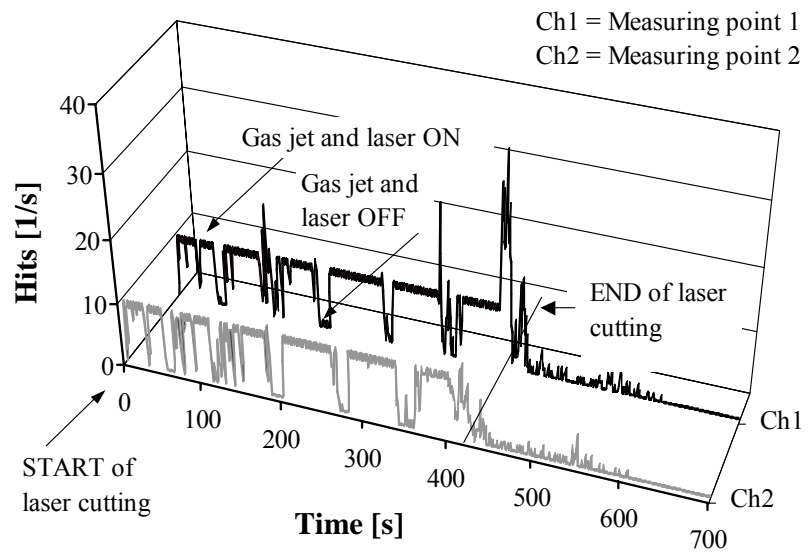

a)

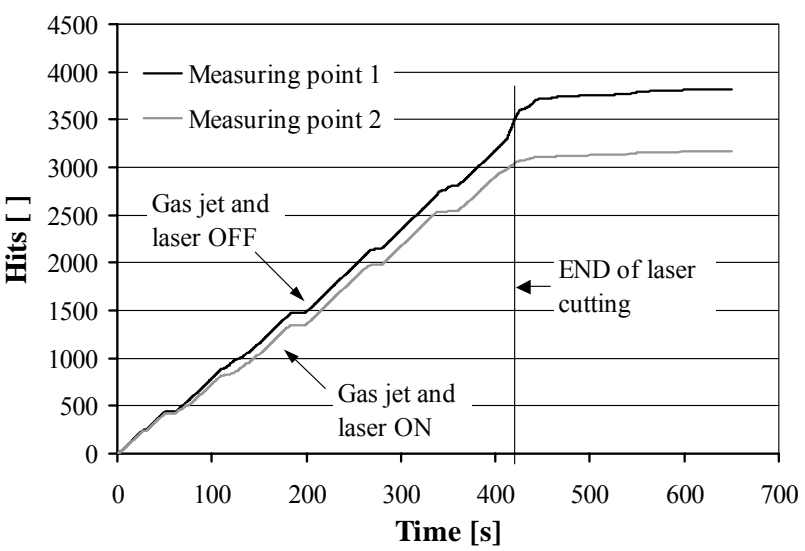

b)

Fig. 5: (a) Number of AE hits per unit of time and (b) cumulative number of AE hits of individual sensors as a function of lasercutting time.

\section{c) Laser cutting of the mudguard out of the deep-drawn semi-product}

Figures $5 \mathrm{a}$ and $5 \mathrm{~b}$ show the number of $\mathrm{AE}$ hits per unit of time and cumulative number of $\mathrm{AE}$ hits of the individual sensors as a function of the laser-cutting time for a mudguard. A comparison of the diagrams in Figs. 4 and 5 shows that there is AE present during the cutting-out of the mudguard even with a free laser-head travel, i.e. in the absence of the laser beam and of the cutting-gas jet. There is also AE after cutting of the mudguard. These AE signals are, in opposition to the AE signals generated by the cutting-gas jet, mainly of discrete character, their 
duration ranging between some $10 \mu \mathrm{s}$ and some $10 \mathrm{~ms}$. It is inferred that these signals are a result of some events at the micro-level in the mudguard material.

Figures 6 and 7 show, for both cases presented in Figs. 4 and 5., the diagrams showing the maximum amplitude of the individual $\mathrm{AE}$ signals captured in a certain time period. In the diagrams the continuous AE signals mainly concentrated in a horizontal line. The average maximum amplitude of the continuous AE signals resulting from the cutting-gas jet when the laser beam is not activated amounts to around $71 \mathrm{~dB}$. A comparison of the average amplitudes showed that the average maximum amplitude of the continuous AE signals obtained in laser cutting is by around $16 \%$ higher than that obtained in the laser-head travel and with just the cutting gas jet present. The average amplitude of the discrete AE signals after laser cutting is lower and amounts to around $57 \mathrm{~dB}$. The range of the maximum amplitudes of the discrete $\mathrm{AE}$ signals is large and varies between $40 \mathrm{~dB}$ and $100 \mathrm{~dB}$.

Mode 1 of cutting-out the mudguard

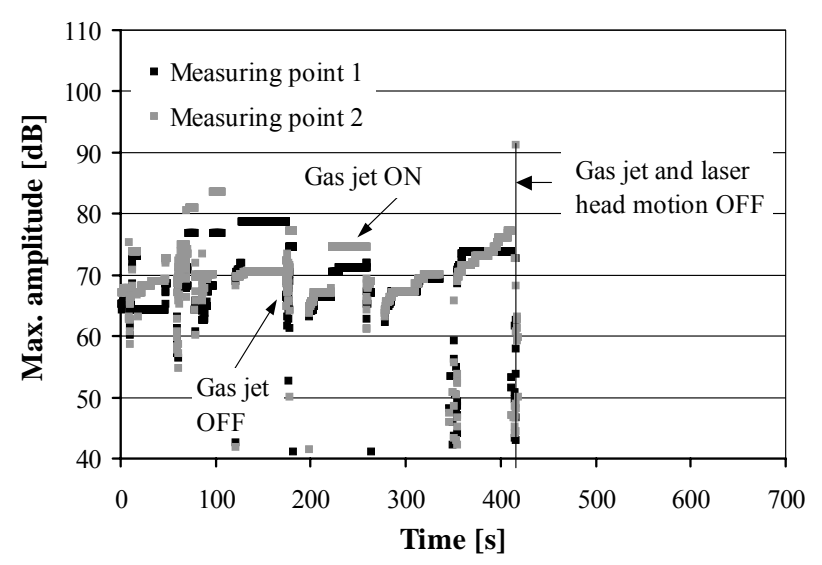

Fig. 6: Maximum amplitude of individual AE signals captured in certain time period during laser-head travel with just cuttinggas jet - no cutting.

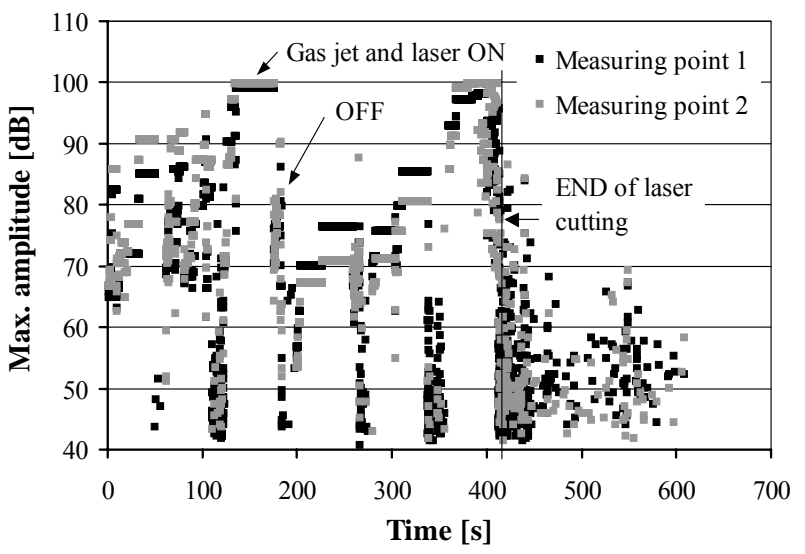

Fig. 7: Maximum amplitude of individual AE signals captured in certain time period during laser cutting.

From the results obtained it can be inferred that it is possible, primarily with reference to the duration and partly also to the maximum amplitude, to efficiently distinguish the AE signals due to the cutting-gas jet from those due to various events in the material.

The large range of duration of the discrete AE signals and also the relatively large range of the maximum amplitudes indicate a great variety of the events in the mudguard material. The discrete AE signals with a relatively high maximum amplitude, i.e. above $70 \mathrm{~dB}$, is attributed to the generation and propagation of micro-cracks and other similar events at the micro-level [2]. A cause for the occurrence of such events may be cutting and the related material separation. The events of this type may occur also during the material deformation due to residual-stress releasing in the deep-drawn semi-product. This applies in case when in the material are defects such as hard and brittle metal inclusions, which can break during elastic or plastic deformation of the material.

The discrete signals with an amplitude below $70 \mathrm{~dB}$ are most probably due to the events related to the material deformation such as moving dislocations, slippage, twinning, friction between grain boundaries, and similar [2]. The diagram in Fig. 7 indicates that during the free laser-head travel and after cutting-out of the mudguard a large quantity of AE signals with the amplitude below $70 \mathrm{~dB}$ generates.

The discrete signals may result also from the events directly related to the cutting process such as material melting and evaporation, blowing-out of the melt and material solidification with reference to the cutting conditions. The discrete AE signals with the low and high amplitudes can 
be generated during cutting also due to the cutting-gas jet. This is anticipated from the data shown in Fig. 6 and the duration of the individual signals.

\subsection{Correlation between acoustic emission and deformations}

For the assessment of the events in the material, a relation between deformation and an AE signal is to be established. This sub-heading will deal simultaneously with the results of AE measurement and deformation measurement during and immediately after laser cutting-out of the mudguard. In that manner both modes of cutting-out of the mudguard will be discussed (Fig. 2). The results obtained with each mode of cutting-out the mudguard are shown as two types of diagrams. The first type of diagram, shown in Figs. 8 and 10, represents the AE signal energy and the mudguard deformation in the y direction (Figs. 3a and 3b) in dependence of time. The second type of diagram, shown in Figs. 9 and 11, represents the number of AE hits of a sensor per unit of time and the mudguard deformation in the y direction in dependence of time. The diagrams in Figs. 8 and 9 refer to mode 1 of cutting-out and Figs. 10 and 11 to mode 2. In the individual diagram the duration of the individual cut is shown as a full line parallel to the abscissa with the number of cut. Free laser-head travel between the individual cuts is indicated by a dashed line.

Before the treatment of the correlation between $\mathrm{AE}$ and deformations, the deformations measured with both modes of cutting-out the mudguard will be discussed.

\section{a) Mudguard deformations with cutting mode 1}

The diagrams in Figs. 8 and 9 show that with cutting-out mode 1 typical deformations were measured only during cut 2 , cut 3 , and cut 6 , i.e. in the course of cutting out the right mudguard, at which the measuring rosettes were mounted (Fig. 1). The influence of cutting-out the left mudguard on deformations of the right mudguard is minimum. The strongest deformations of the right mudguard occurred during cut 6 at the measuring point 1 located at the beginning of cut 6 .

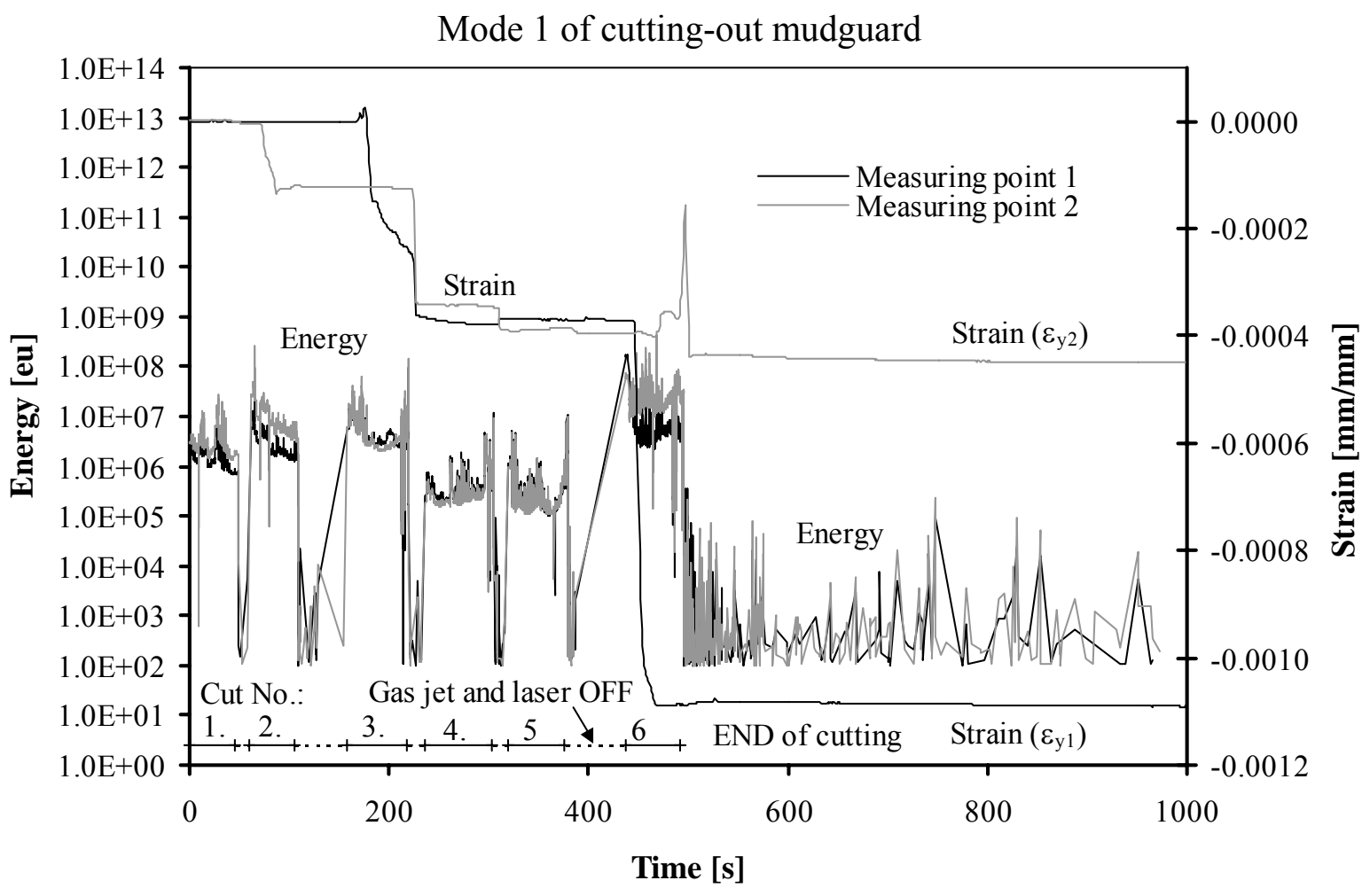

Fig. 8: AE signal energy and deformations of right mudguard in y direction as a function of time. 


\section{b) Mudguard deformations with cutting mode 2}

As distinguished from mode 1 , mode 2 was applied only to cut out the right mudguard from the deep-drawn semi-product. The right mudguard deformation occurring in the course of the second mode of cutting-out is shown in the diagrams in Figs. 10 and 11. In this case too the strongest deformations were measured during the last, i.e. cut 3 , and at measuring point 1 .

\section{c) Correlation between acoustic emission and mudguard deformations with cutting-out} modes 1 and 2

The diagrams in Figs. 8 through 11 make it possible to see that the mudguard deformations were measured only during the cutting-out process. Contrarily, there is AE occurring also during free laser-head travels and after cutting-out of the mudguard. This difference is attributed to the fact that it is possible with measuring rosettes to measure only local deformations at the measuring point where the measuring rosette is mounted, whereas with AE measurement the events are sensed also at distance. In generally with AE measuring events occurring no matter where in the material of the deep-drawn semi-product, i.e. in the mudguard material can be sensed.

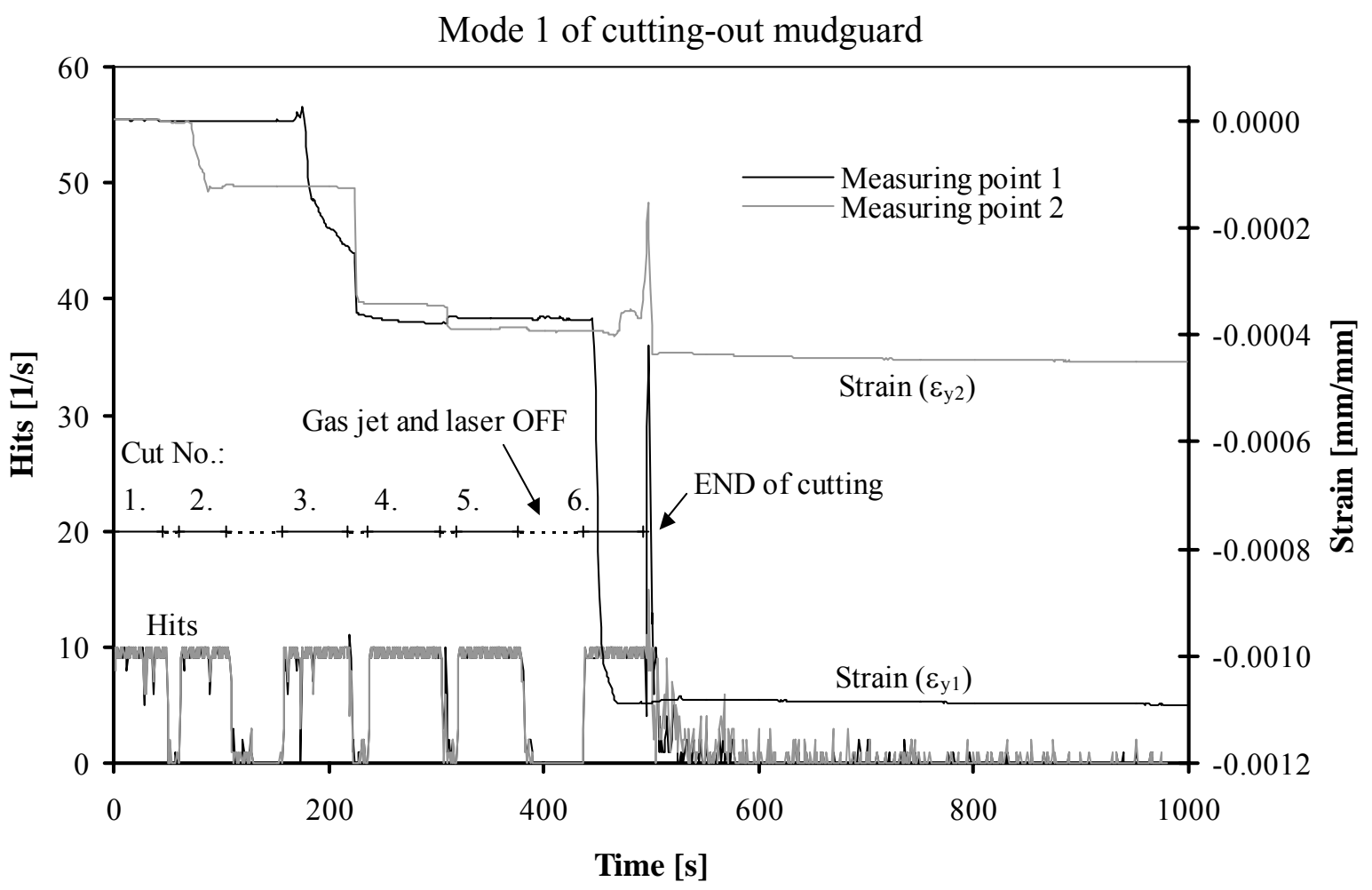

Fig. 9: Number of AE hits of sensor per unit of time and deformations of right mudguard in y direction as a function of time.

The diagrams in Figs. 8 and 10 make it possible to see that an increase in the AE signal energy above the level induced by the cutting-gas jet coincides with the mudguard deformations. The increase in the AE signal energy, however, is not so explicit.

The diagram in Fig. 9 makes it possible to see very well the moment when the mudguard became separated from the deep-drawn semi-product. At this very moment the number of AE hits of sensors per unit of time increases strongly. This parameter of the AE signal can serve, with cutting-out mode 1 , as a good indicator of the end of cutting-out mudguard.

With cutting-out mode 2, however, the greatest number of AE hits occurs after the end of cut 2, whereas the strongest deformations are found in the course of cut 3 , similar as with cutting-out mode 1. 


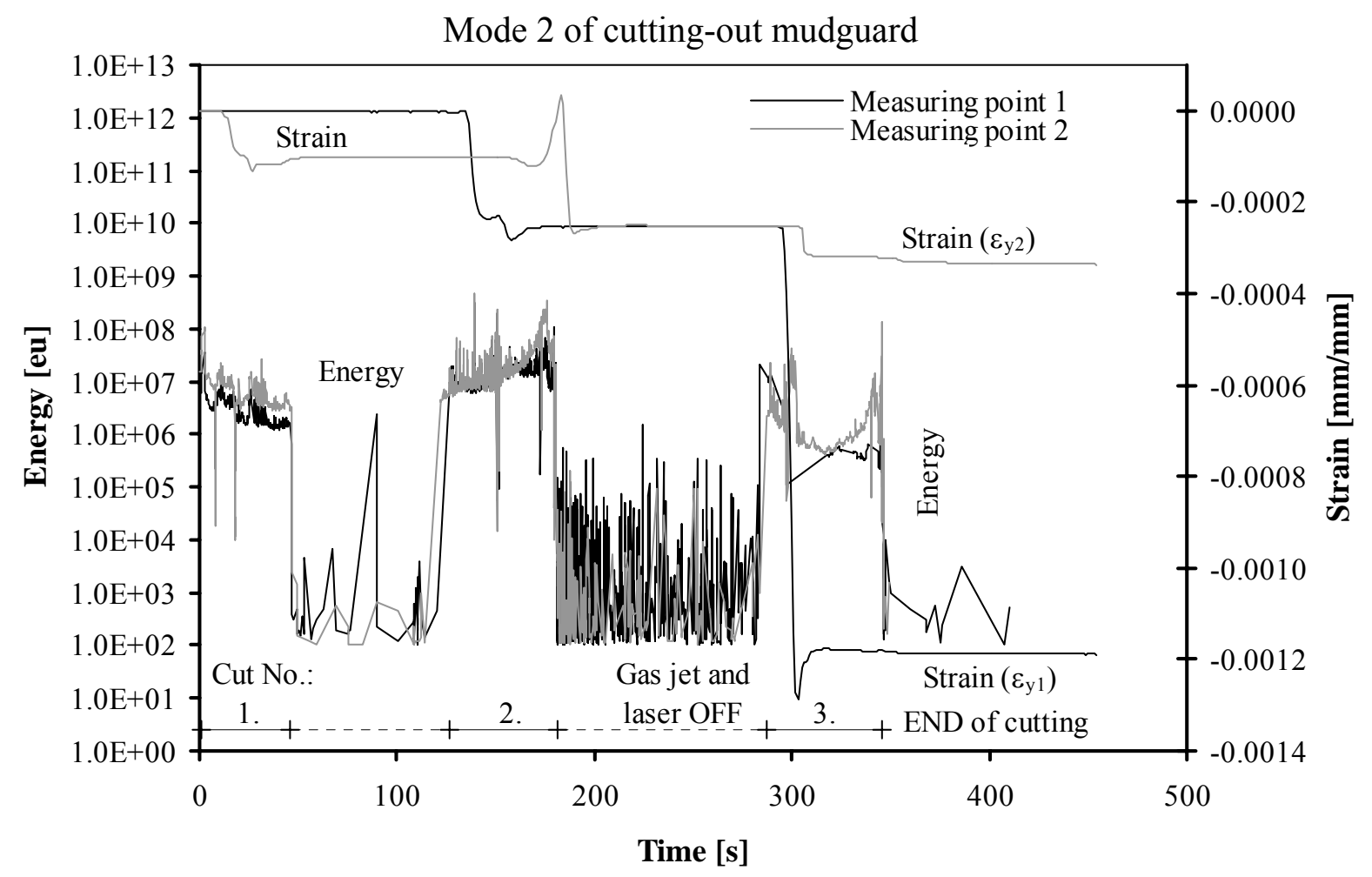

Fig. 10: AE signal energy and deformations of right mudguard in y direction as a function of time.

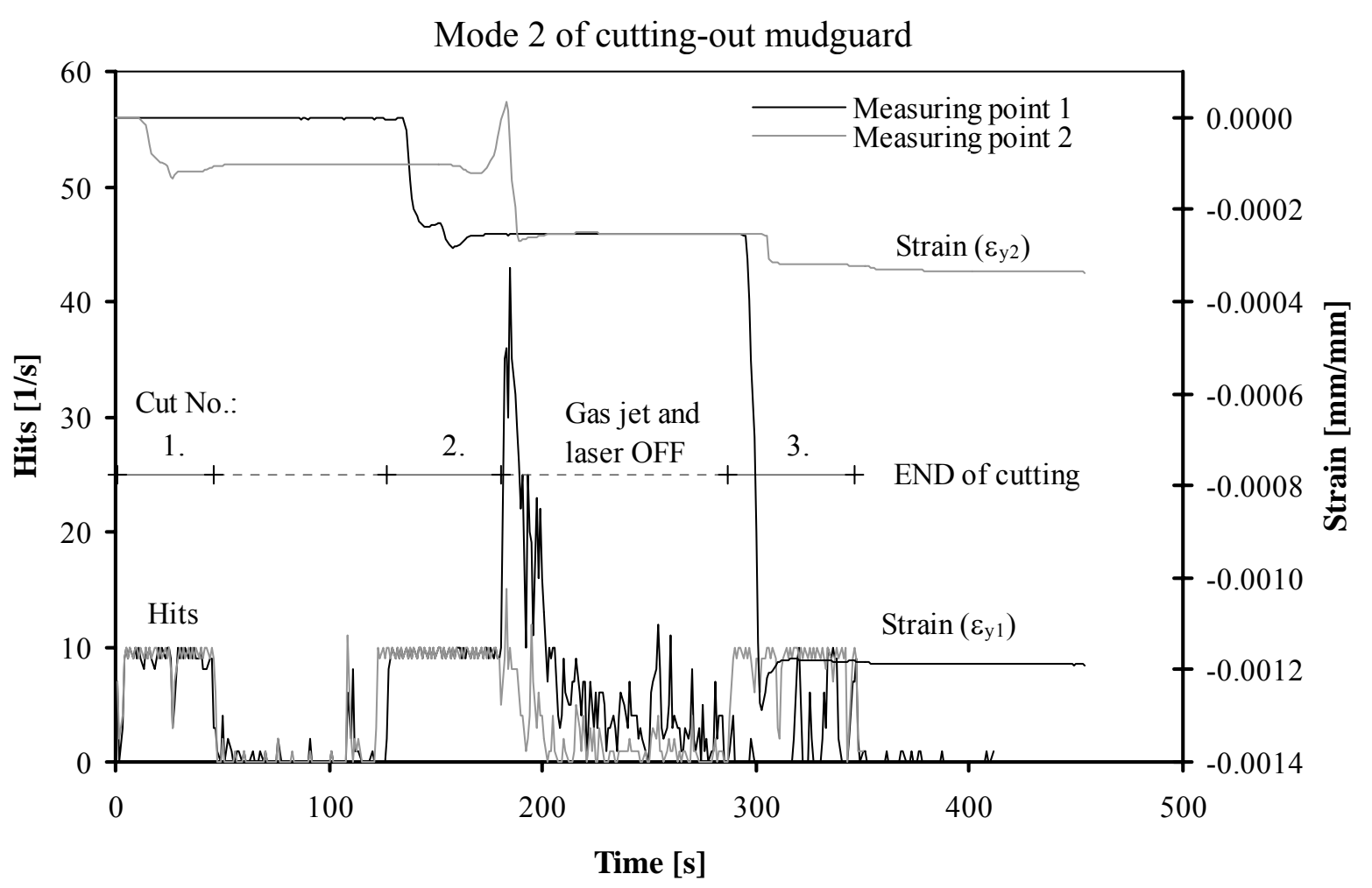

Fig. 11: Number of AE hits of sensor per unit of time and deformations of right mudguard in $y$ direction as a function of time. 


\section{Conclusions}

The investigation presented is considered a basic step towards the control and optimization pf laser cutting-out process for deep-drawn products by means of AE measurement.

It was found that the main AE source during laser cutting is the cutting-gas jet. The "true" AE present during the laser cutting process and immediately after cutting-out the mudguard is related to releasing of residual stresses present in the deep-drawn semi-product and the processes produced in the material by the absorbed laser light.

From the results obtained it may be inferred that the control of the laser-cutting process by AE measurement provides useful additional information on the process itself and events in the workpiece material. It should be mentioned that applicable data on events in the material can be obtained only with an exacting analysis of the AE signals captured.

\section{References}

[1] Steen W.M.: Laser Material Processing, Springer-Verlag, London, 1996.

[2] Vallen H.: AE Testing Fundamentals, Equipment, Applications, NDT.net, Vol. 7, No. 9, 2002 (http://www.ndt.net/article/v07n09/05/05.htm).

[3] Dreyfuss R.H., Bailey S.J. et al: Annual Book of ASTM Standards, Section 3: Metals Test Methods and Analytical Procedures, Vol. 03.03: Nondestructive Testing, ASTM International, Baltimore, 2003.

[4] Grabec I., Leskovar P.: Acoustic emission of a cutting process, Ultrasonic, Vol. 15, No. 1, 1977, 17-20.

[5] Grabec I., Govekar E., Gradišek J., Klocke F., Saxler W., Baus A.: Analysis of acoustic emission of manufacturing processes $=$ Analiza akustične emisije obdelovalnih procesov, Zbornik referatov Prvega kongresa Slovenskega društva za akustiko z mednarodno udeležbo in razstavo, Portorož, 1998, 1-18.

[6] Grabec I., Govekar E., Susič E., Antolovič B.: Monitoring manufacturing processes by utilizing empirical modeling, Ultrasonics, Vol. 36, No. 1/5, 1998, 263-271.

[7] Li X.: A brief review: acoustic emission method for tool wear monitoring during turning, International Journal of Machine Tools \& Manufacture, Vol. 42, No. 2, 2002, 157-165.

[8] Grad L., Grum J., Polajnar I., Slabe J.M.: Feasibility study of acoustic signals for on-line monitoring in short circuit gas metal arc welding, International journal of machine tools \& manufacture, Vol. 44, No. 5, 2004, 555-561.

[9] R. D. Rawlings, W. M. Steen: Acoustic Emission Monitoring of Surface Hardening by Laser, Optics and Lasers in Engineering, Vol. 2, No. 3, 1981, 173-188. 